\title{
Corrigendum: Streptomyces lactacystinicus sp. nov. and Streptomyces cyslabdanicus sp. nov., producing lactacystin and cyslabdan, respectively
}

\author{
Akira Také, Atsuko Matsumoto, Satoshi Ōmura and Yōko Takahashi \\ The Journal of Antibiotics (2017) 70, 113; doi:10.1038/ja.2016.103
}

Correction to: The Journal of Antibiotics (2015) 68, 322-327; published online 10 December 2014; doi:10.1038/ja.2014.162

The authors of the above article noticed and corrected the following error in the publication of The Journal of Antibiotics (2015) 68, 719; doi:10.1038/ja.2015.89.

In the Abstract and the 'Description of Streptomyces lactacystinicus sp. nov.' sub-section under the Results and Discussion section, DSM number for strain OM- $6519^{\mathrm{T}}$ was wrong. It should have been read OM-6519 ${ }^{\mathrm{T}}\left(=\right.$ NBRC $110082^{\mathrm{T}}$, DSM $\left.42136^{\mathrm{T}}\right)$.

Below is the corrected version of the subsection 'Description of Streptomyces lactacystinicus sp. nov.'.

\section{Description of Streptomyces lactacystinicus sp. nov.}

Streptomyces lactacystinicus (lac.ta.cys.ti'ni.cus. N.L. n. lactacystinum, lactacystin; L. masc. suff. -icus, suffix used with the sense of pertaining to; N.L. masc. adj. lactacystinicus, pertaining to lactacystin, a proteasome inhibitor produced by the organism).

A Gram-positive aerobic actinomycete that forms straight spore chains. The spores are cylindrical with a rugose surface and size of
$1.1-1.3 \times 0.6-0.7 \mu \mathrm{m}$. Grows well on ISP 2, 3, 4, 5, 6 and 7, and forms brown colonies. Gray aerial mycelia are abundantly produced on ISP 2 and 3. A yellow soluble pigment is produced. Growth occurs at $15-37^{\circ} \mathrm{C}$ and $\mathrm{pH} 5-10$. No growth occurs at $5 \%$ (w/v) $\mathrm{NaCl}$. Melanoid pigment is not produced. Milk is coagulated and peptonized. Nitrate is reduced to nitrite. Gelatin is not liquefied. Starch is hydrolyzed, but cellulose is not. D-Glucose, D-fructose, sucrose, L-aspartic acid, L-threonine, glycine, L-phenylalanine, L-arginine and L-ornithine are utilized as sole carbon and nitrogen sources. L-arabinose, D-xylose, raffinose, melibiose, D-mannitol, L-rhamnose, myo-inositol, L-methionine and D-valine are not utilized. Whole-cell hydrolysate contains LL-diaminopimelic acid as the diamino acid, in addition to glucose, ribose and rhamnose. The polar lipids mainly consist of phosphatidylethanolamine. The major menaquinones are MK-9 $\left(\mathrm{H}_{6}\right)$ and MK-9 $\left(\mathrm{H}_{8}\right)$. The predominant fatty acids are $\mathrm{C}_{16: 0}$, anteiso- $\mathrm{C}_{15: 0}$ and iso- $\mathrm{C}_{15: 0}$. The $\mathrm{G}+\mathrm{C}$ content of the genomic DNA of the type strain is $73 \mathrm{~mol} \%$. The type strain, OM-6519 ${ }^{\mathrm{T}}$ ( = NBRC $110082^{\mathrm{T}}$, DSM $42136^{\mathrm{T}}$ ), was isolated from soil from Inba, Chiba, Japan, and produces lactacystin, a proteasome inhibitor. 